\title{
Toward More Effective Storytelling for Raising Environmental Awareness in Young Students
}

\author{
Yannis Hadzigeorgiou ${ }^{1}$, Gillian Judson ${ }^{2}$ \\ ${ }^{1}$ University of the Aegean, Greece \\ ${ }^{2}$ Simon Fraser University, Canada \\ Email: hadzigeo@rhodes.aegean.gr
}

\begin{abstract}
This paper addresses the need to reclaim the value of storytelling as a tool for raising environmental awareness in young children. In distinguishing between 'knowledge' and 'awareness', the paper discusses the role that the sense of wonder evoked through shaping topics in story-form can play in encouraging awareness. Through imaginative and emotional engagement with issues and ideas, children can feel the significance of the natural world around them. The role of the Story of the Universe which presents the natural environment as a living organism, in which human beings and Nature co-exist, is also discussed.
\end{abstract}

Keywords: Environmental awareness, storytelling, wonder

\section{Introduction}

No doubt, students learn, both formally and informally, many things, including those concerning the natural environment. An assessment, in fact, of students' representations of the various concepts, that they have supposedly learned, can be a measure of their knowledge. Doubt, however, could be raised in regards to their awareness of what they really know. Gardner (1991) has been very critical of the fact that even college and university students and graduate demonstrate the same kind of naïve understanding as five years old when it comes to solving basic problems, especially in physics and mathematics. In his The Unschooled Mind, Gardner (1991) wonders at and about such a predicament.

It is for these reasons that we consider the delicate distinction between knowledge, meaning representations of the world, that students are either presented with (that is the traditional representational pedagogy) or that they construct through personal experience (that is the constructivist pedagogy) (Biesta \& Osberg, 2007), and awareness, meaning one's ability to notice things, or a state of being fully conscious of what one knows or what one has learned. This notion of awareness acquires a special significance in the new millennium, since the need for raising environmental awareness in the context of education has become more pressing than ever (Judson, 2010; Slattery \& Rapp, 2003).

It is believed that environmental awareness starts in young children with the development of an emotional bond with Nature. Through first hand experiences in Nature that encourage enjoyment and that foster a sense of wonder (Kellert, 2002; Wilson, 1994) and an appreciation of natural beauty (Richards, 2001), children can develop emotional attachments. According to Wilson's (1993) "biophilia hypothesis" (i.e., human beings have an innately emotional relationship with other living organisms), the emotional bond between children and Nature is something they are born with and, thus, they feel drawn to engage with living things. Still, the role of indirect experiences cannot and should not be dismissed. In fact, some advocates of the "biophilia hypothesis", have suggested that the genetic bond between children and Nature may very well be a weak one, thus requiring additional learning experiences (Kahn, 1997; Kellert, 2002; see also Clayton \& Opotow, 2003). Considering the fact that children grow up in a highly technological world, and many of them in cities have very limited if any opportunities to be in Nature, indirect learning opportunities deserve special attention, if indeed the development of environmental awareness is an educational goal. Even in the case of children who live in the countryside, the fact that every year fires and also other natural disasters destroy large parts of their 'local' natural environment (see Hadzigeorgiou et al., 2010), makes the raising of environmental awareness through indirect learning experiences a worthwhile educational goal in the new era. This article explores the role story can play in the development of children's environmental awareness. 


\section{The Potential Role of Storytelling for Raising Environmental Awareness}

In the context of environmental education storytelling has been considered an effective teaching strategy in cases in which direct experience is impossible or unmediated, and also in cases in which the consequences of our experience are negative or undesirable (De Young \& Monroe, 1996; Hadzigeorgiou et al., 2010). However, storytelling can be considered an effective strategy across the curriculum, especially when raising young students' environmental awareness is an educational goal (Hadzigerorgiou et al. 2010; Judson, 2010).

Indeed, because of its power to engage the emotions, storytelling can help students transcend traditional dichotomies, such as those between fact and fiction, reality and epistemic subject. It is very often the case that students (i.e., epistemic subjects) at all levels of education do not become involved with their object of study and reality in general (i.e., epistemic object). And this is why Dewey (1916/1966) argued against such dualisms as "knowledge and the knower", "the child and the curriculum", school and society". Such dualisms can help explain the lack of motivation on the part of students. Storytelling, by emotionally involving the listener, helps bring closer reality, as an epistemic object, and students. Gough (1993), in fact, has pointed that out: in storytelling there is a "relatedness of the observer and the observed and the personal participation of the knower in all acts of understanding" (p. 621).

Apparently, the power of the story to draw the listener into its plot helps teachers move away from what Dewey (1916/1966) called "the spectator theory of knowledge", which can be observed in classrooms even today (Hadzigeorgiou \& Skoumios, 2013). This shift toward more participatory forms of engagement in learning is crucially important if student engagement with subject matter is to be encouraged, especially when the latter refers to the natural environment. Thus, in the case in which this relatedness or sense of participation with subject matter refers to the student and the natural environment, when the latter, directly or indirectly, 'features' in the plot of the story, the emotional bond, necessary for the development of environmental awareness, can also be fostered.

However, this emotional bond is likely not enough for the development of environmental awareness. If environmental awareness refers to students' ability to notice features of the natural world and relationships within nature, and also notice interrelationships between issues, ideas and human life (see Hadzigeorgiou \& Skoumios, 2013; Wals, 2011) then such awareness does not necessarily take place through direct experiences in Nature, even when an emotional bond with Nature has already been formed. Young children may very well have developed a love for Nature but still be unaware of how things work, of how things relate to one another. It would be as naïve to think that young children can raise their awareness of environmental issues and their effects on human life by simply listening to a story that connects them emotionally with Nature, as it is to think that they can understand the process of photosynthesis by looking at trees, or even by observing their leaves, in the sunlight! It is important, therefore, that facts and ideas about the natural environment and their interrelationships with human life be deliberately embedded in the plot of the story. The topics we teach need to be story-shaped.

At the same time, what also needs to be pointed out is that approaching the development of environmental awareness through storytelling in various disciplinary areas, or in interdisciplinary units, can be quite challenging. The reason is that the natural world must always be the topic of focus during the narrative (as when teaching science or a unit that specifically calls for the study of the natural environment), or must, at least, at some point during the narrative, be noticed as a significant entity. Even when students' object of study is a socio-scientific issue (e.g., genetically modified food, transportation, overpopulation), an issue with an explicit environmental dimension (e.g., water pollution, global warming, acid rain), a natural phenomenon (e.g., a flash of lightning, the water cycle, photosynthesis, aurora borealis), an object or entity from the natural world (e.g., a piece of rock, a flower, a glass of water), or a science idea (e.g., heat, light, energy), the idea of the natural environment and its interrelationships with human life must be explicit in the plot of the story. This is a point worth stressing, especially in the context of contemporary education, and science education in particular, where one may speak of an "ontological reversal", that is a process whereby symbols and technological artifacts acquire a higher ontological status than the experience itself (see Harvey, 1987). The possibility of fostering a sense of wonder deserves particular attention, at least more attention than has received in 
the past, since it can raise students' awareness of the significance of issues and ideas by making them notice these issues and ideas, and their interrelationships with human life.

\section{The Role of a Sense of Wonder}

The idea of wonder, as the engine of all intellectual inquiry, is not new (Toulmin, 1967). Recently, however, there has been a renewed interest in wonder, as a cognitive tool that can enlarge and enhance students' ability to think and learn (Egan, 2005; Egan, Cant, \& Judson, 2013; Hadzigeorgiou, 2001; Judson, 2010). Moreover, the critique of analytic, instrumentalist and "invasive" rationality, and hence the need for caring and surprise, as two approaches to gain knowledge about Nature (Bonnet, 2004), points to the centrality of wonder as a means to raising environmental awareness.

Indeed, if wonder involves a feeling of surprise coupled with some kind of awareness (e.g., that one's knowledge is incomplete or erroneous, that some phenomena exist at all), then environmental awareness, as knowledge of the interrelationships of issues/problems and human life, could be raised through the plot of a story that explicitly addresses those interrelationships and helps evoke a sense of wonder about them. Although this is easier with environmental and generally socio-scientific issues, since the interrelationships between issues and human life are either explicit or implicit, and therefore more easily perceived, in the case that the object of study is a natural phenomenon, an object from the natural environment or even a science idea, the interrelationships need to be made quite explicit in the plot of the story.

For example, the fact/issue that the corn used to produce ethanol used by an SUV in one day can feed as many as a hundred people for more than a week, can help evoke a sense of wonder about human behavior, which can have an effect on human life. By the same token, in teaching about the water cycle, what can evoke wonder is the idea that the water we drink is the same water that dinosaurs drank millions of years ago. This idea has the potential to make students wonder about the age of the water on the planet, and what humans do with it has consequences for all people on the planet. Similarly, in teaching about plants and photosynthesis, ideas that can help evoke wonder is that of all living organisms it is only plants that can support human life, and that a tiny leaf, that is, such a familiar and taken-for-granted thing, is a whole factory of oxygen. Indeed, trees, as being one of the most productive plants on earth, can do immense amounts of good for humans.

In one year, an average tree inhales 12 kilograms (26 pounds) of carbon dioxide (a "greenhouse gas") and exhales enough oxygen to keep a family of four breathing. A tree does this through their leaves, which are held up by the tree's trunk to get as much sunlight as possible, and which also give nourishment to the tree and the roots, which in turn gather nutrients from the soil to hold up the whole structure. Thus the story about trees is an amazing and 'wonder-full' story of complex cooperation among roots, trunk, branches, twigs, and leaves, creating one of the most beautiful and beneficial plants in the world (Judson, 2010).

It is the 'wonder-full' ideas about anything to be taught that must be made explicit in the plot of the story that teachers use with students. The process by which teachers will find that central source of wonder begins when they identify for themselves what is emotionally engaging about the topic. What do you, the teacher, find interesting and amazing about the topic? Once you identify this source of emotional significance then you have the "story" you will share - as would a reporter - with students. You can create the imaginative context in your classroom in which teaching becomes storytelling. (For support with this process and more information about what other ways to shape your teaching in storyform visit the Imaginative Education Research Group website: www.ierg.net).

These ideas will help evoke a sense of wonder thus making something that students consider usual and ordinary look unusual and extraordinary (Hadzigeorgiou, 2001). This is the power of wonder, and this is how everyday and taken-for-granted objects and events acquire a new significance and meaning. And this role of wonder, as a tool that helps students view things in new ways, is in line with a view of knowledge inspired by complexity theory, and more specifically by the notion of 'strong emergence'. Knowledge, from such a perspective, helps people perceive a new realty (Biesta \& Osberg, 2007), which, however, is necessary for helping students, especially young children, view the natural environment in new ways. There is empirical evidence that the experience of wonder can indeed make young children view trees in a new way that raises their environmental awareness (Hadzigeorgiou et al., 2010). 
It is time we looked at wonder in a new way too, and reclaimed its value in education, especially in early childhood education. For it is the sense wonder about how ideas and issues relate to human life that has the potential to foster and raise students' awareness of their personal and wider significance. Egan (1992) gives an excellent example concerning how a sense of wonder about a useless object, that is, a broken styrofoam cup, can enlarge its significance for human life. Instead of seeing that cup as simply an environmentally damaging waste, Egan (1992) gives a 'romantic' alternative: he considers it a symbol of a heroic quality, that is, a symbol of "an immense ingenuity". Indeed we can hold burning liquids in it without our hand being burned. As he points out:

We can enlarge its significance by considering it as a part of the heroic journey that is the human struggle to shape the world more closely to our desires, to find release from the constant toil, sickness, and pain that have been the lot of most people most of the time [...] The knowledge of chemical and physical processes that have gone into its design and making is prodigious. And we have learned the environmental costs entailed in applying this knowledge to create this convenience, and we are as a society recognizing that we must satisfy this particular desire in other ways that do not threaten our harmony with the natural world. One can flash such thoughts through the mind in less than half a second [...] They are associations that come with romantic image of the broken cup. (Egan, 1992, pp. 76-77)

It is clear, from what Egan says, that a sense of wonder about an object, which after its use ends up in the trash, can help raise awareness of a number of interrelated ideas, which, in turn, helps raise environmental awareness. Whether the science lesson is a socio-scientific issue (e.g., "environmental waste", or the chemistry of materials), the previous example shows that the significance of what can be considered a useless object (after it has been used) can be the starting point for various associations concerning science, the environment, and human life. It also shows the possible effect on one's own life that wonder can have (i.e., how one feels, thinks, behaves and acts).

Thus stories, whether about concepts such as energy, the water cycle, and the atmosphere, or about socio-scientific issues, such as biodiversity, the greenhouse effect, nuclear waste and coastal pollution, are pedagogically valuable because they can leave students feeling something about the topic and can promote the idea of relatedness of human beings and nature. But how can this be done? In helping the students learn, for example, about the electric current (to take an idea that supposedly does not have an explicit environmental dimension), a concept map or a web of ideas that helps the teacher or curriculum designer identify possible connections between the concept to be learned and human life from a personal and a wider perspective, can provide the basis for the ideas to be included in the plot of the story. Teachers can make these relationships part of a "story" not by creating fictions, but by revealing in their teaching the wonder in the topics they teach. Lessons that are story-shaped will explicitly address interconnections (such as the effect of energy consumption on the environment--as a result of using more electricity--the search for alternative sources of energy, the social consequences of current electricity, as a social good, the economic considerations of producing current electricity, as a good that is available to all homes on the planet, etc.) and will leave students feeling some of the wonder inherent in these connections. The plot can include one or more interconnections and the moral that accompanies them. Apparently, this kind of work (i.e., the concept map or web and the creation of a plot) requires a lot of imagination and shows that logico-mathematical and narrative thinking can work together, if effective learning is our goal (see www.ierg.net for story-shaped units and lessons). However, an interconnection with the wider world, particularly Nature, is also possible, as is discussed in the next section.

\section{The Story of the Universe}

In considering the crucial importance of global awareness in the context of contemporary education, and the fact that global awareness and environmental awareness are intricately linked (Hadzigeorgiou \& Skoumios, 2013; Selby, 1998), then helping students gain a larger perspective is not simply important as a learning activity; it is a goal worth pursuing. For it is the bigger picture of the planet and a global perspective that can help promote a larger concept for the natural environment. And this perspective is needed, since the natural environment is a much larger concept than what some people may think (i.e., for people whose environmental concern stops at their yard fence). In addition, the development of a global perspective is crucially important because students can become aware of the state of the planet as 
a whole and thus develop an understanding of how the various systems (e.g., cultural, economic, political, technological, ecological) are linked and how these systems and their interrelationships affect the natural world. From such a perspective, global awareness can make an important contribution to environmental awareness.

However, by considering a global perspective on education, students' involvement with the learning process is also an issue that is attended to. The fascination that human beings have shown toward, and their attempt to understand, the Universe as a whole has been pointed out by the philosopher Stephen Toulmin:

Ever since human beings first began to reflect about, and to discuss, their situation within the world of natural things, their most comprehensive ambition has been to talk sense about the Universe as a whole. (Toulmin, 1982, p.1)

One question, however, remains to be answered: what kind of stories can we tell students if global awareness is our goal? As has already been pointed out, science stories in the main address the learning of science content knowledge. This cannot help students develop a global perspective. What are then the options that science education has? One option, of course, is to include in the curriculum problems and issues with a global dimension (e.g., overpopulation, natural disasters), which means that plot of the story will address these issues and their interrelationships with human life (Hadzigeorgiou \& Konsolas, 2001).

Another option is to consider the possibility to tell students the story of the Universe. In fact, some science stories can also tell the story of humanity and the universe. The story about atoms, to take another example, is a story about the universe. However, O'Sullivan (2002), points out that:

The difficulty is that scientists have until recently given us the story only in its physical aspects not in the full depth of its reality or in the full richness of its meaning. The greatest single need for survival of the earth or of the human community in the late twentieth century is for an integral telling of the Great Story of the Universe. (O'Sullivan, 2002, p. 7)

It is interesting to note that Swimme (1988), in line with the idea of the "Great Story of the Universe", talked about "The Cosmic Creation Story", that is, a story about the evolution of human life since the Big Bang:

Rocks, soils, waves, stars - as they tell their story in 10,000 languages throughout the planet, they bind us to them in our emotions, our spirits, our minds, and our bodies. The Earth and the universe speak in all this. (Swimme, 1988, p. 56)

Littledyke (1996) points out that this particular story is a story of science, but "it is both poetic and meaningful, giving both a sense of human ancestry and connection with the cosmos" (p. 209). This connection with the cosmos is quite crucial in postmodern education.

A word of caution, however, should also be said at this point. In talking about the "Story of the Universe", one may be tempted to interpret it as 'the one true story' about the universe. Given the loss of faith in objectivity, as well as the blurred boundaries between fact and fiction, the story of the universe, from a postmodern perspective, should invite deconstruction and skepticism (see Gough, 1993). But in so far as it approaches reality from multiple perspectives, in so far as it encourages relatedness of nature and human beings, and is also meaningful to the students, it can be considered pedagogically appropriate.

It also deserves to be pointed out here that the "Story of the Universe" or rather "A Story of the Universe", has two important and interrelated advantages: First, it increases the possibilities for students' connection with the wider world, and second, it encourages the (re)connection of the self with Nature. In regard to the former, "the Great Story of the Universe" (or a story of the Universe), provides opportunities for students' connection with the wider world, of which the natural environment is a part. This is crucial for young students, who perceive the natural world in a narrow way (i.e., by associating it with their immediate natural environment). Moreover such a story may very well help with the development of an ethics of caring about what is distant and remote and not just about what is near to them. Indeed, because the global perspective has both spatial and temporal dimensions storytelling can address both local-global interconnections with respect to the various issues, and temporal interconnections with respect to these issues. In regard to the (re)connection of self and the natural environment, the "Great Story of the Universe" is a story in which, both the story-teller and the student are part of it. Gough (1993) has argued, that although storytelling has helped to raise our awareness of the nature and extent of numerous environmental problems, these problems may themselves have 
resulted from modern science's stories, in which the story-maker or story--teller is 'detached' from the natural environment. In this sense "The Great Story of the Universe" facilitates the reconnection of human beings with Nature. It is this reconnection that helps raise environmental awareness, through the awareness that "survival is the one universal value that transcends the proclamation of difference" (Gough, 1993, p. 610).

\section{$5 \quad$ Summary and Final Comments}

In this paper we explored the possibility of raising environmental awareness through storytelling, specifically by evoking a sense of wonder about the natural environment and its interrelationships with human life, and by including the Story of the Universe as one of our stories. We also pointed to an important teaching implication, namely, the centrality of keeping the natural environment in focus throughout the story-shaped lessons and units we create.

If wonder gives things their infinite significance (Hove, 1996; Verhoven, 1970), and if the mind is indeed a narrative concern (Bruner, 1986; 1990; Egan, 1992, 2005), then the values of wonder and storytelling need to be reclaimed. For it is 'wonder-full' storytelling that can help children, who will be educated in the twenty-first century, to become aware, through emotional and imaginative engagement, of how significant the natural world is. It is 'wonder-full' storytelling that has the potential to encourage, through an awareness of the personal and wider significance of issues and ideas, the reconnection of human beings with the natural world.

In regard to the "Great Story of the Universe", which incorporates the natural environment as a living organism, in which human beings and Nature co-exist, this particular story can help students to become aware of the interconnection of science, human issues, problems, and their own life. This interconnection, in turn, can facilitate the awareness that the apparent insignificance of some issues and problems can be very significant indeed and affect everyone on the planet.

\section{References}

1. Biesta, G., \& Osberg, D. (2007). Beyond re/presentation: A case for updating the epistemology of schooling. Interchange,38, 15-29.

2. Bonnett, M. (2004). Retrieving nature. Education for a post-humanist age. Oxford: Basil Blackwell.

3. Bruner, J. (1986). Actual minds, possible worlds. Cambridge, MA: Harvard University Press.

4. Bruner, J. (1990). Acts of meaning. Cambridge, MA: Harvard University Press.

5. Clayton, S., \& Opotow, S. (2003). Identity and the natural environment: The psychological significance of nature. 、 Cambridge, MA: MIT Press.

6. Cole, R. (1989). The call of stories. Teaching and the moral imagination. Boston, MA: Houghton Mifflin.

7. De Young, R., Monroe, M. (1996). Some fundamentals of engaging stories. Environmental Education Research, 2,171-187.

8. Dewey, J. (1966). Democracy and education. New York: McMillan.

9. Egan, K. (1986). Teaching as storytelling. London, Ontario: Althouse Press.

10.Egan, K. (1992). Imagination in teaching and learning. London, Ontario: Althouse Press.

11.Egan, K. (2005). An imaginative approach to teaching. Jossey-Bass, CA: San Francisco.

12.Egan, K., Cant, A., \& Judson, J. (Eds.) (2013). "Wonder-full" education. The centrality of wonder in teaching and learning across the curriculum. London, New York: Routledge.

13.Gardner, H. (1991). The Unschooled Mind. New York: Basic Books.

14.Gough, N. (1993). Environmental education, narrative complexity and postmodern science/fiction. International Journal of Science Education, 5, 607-625

15.Hadzigeorgiou, Y. (2001). The role of wonder and "romance" in early childhood science education. International Journal of Early Years Education, 9, 63-69.

16.Hadzigeorgiou, Y., Konsolas, M. (2001). Global problems and the curriculum: Toward a humanistic and constructivist science education. Curriculum \& Teaching, 16, 39-49.

17.Hadzigeorgiou, Y., Prevezanou, B., Kabouropoulou, M., \& Konsolas, M. (2010). Teaching about the importance of trees. A study with young children. Environmental Education Research, 17, 519-536. 
18.Hadzigeorgiou, Y., \& Skoumios, M. (2013). The Development of Environmental Awareness Through School Science: Problems and Possibilities. International Journal of Environmental \& Science Education, 8, 405-426.

19.Harvey, C. (1989). Husserl's phenomenology and the foundations of natural science. Athens, OH: Ohio University Press.

20.Hove, P. (1996). The face of wonder. Journal of Curriculum Studies, 28, 437-462.

21.Judson, G. (2010). A new approach to ecological education. New York: Peter Lang.

22.Kahn, P. (1997). Developmental psychology and the biophilia hypothesis: Children's affiliation with nature. Developmental Review, 17, 1-61.

23.Kellert, S. (2002). Experiencing nature: Affective, cognitive and evaluative development in children. In P. Kahn \& S. Kellert (Eds.), Children and nature (pp.117-151). Cambridge, MA: MIT Press.

24.O'Sullivan, E. (2002). The project and vision of transformative education. In E. O'Sullivan, A. Morrell \& M. O'Connor (Eds.), Expanding the boundaries of transformative learning (pp. 1-12). New York: Palgrave.

25.Richards, R. (2001). A new aesthetic for environmental awareness: Chaos theory, the beauty of nature, and our broader humanistic identity. Journal of Humanistic Psychology, 41(2), 59-95

26.Slattery, P., \& Rapp, D. (2003). Ethics and the foundation of education. Boston: Allyn \& Bacon.

27.Swimme, B. (1988). The cosmic creation story. In D. Griffin (Ed.), The Reenchantment of science (pp.47-56). New York: SUNY Press.

28.Toulmin, S. (1976). Knowing and acting. An invitation to philosophy. New York: McMillan.

29.Toulmin, S. (1982). Cosmolopis: The hidden agenda of modernity. Chicago: University of Chicago Press.

30.Verhoven, C. (1972). The philosophy of wonder. New York: McMillan.

31.Wals, A. (2011). Learning our way to sustainability. Journal of Education for Sustainable Development, 5, 177186 Wilson, E. (1993). Biophilia and the conservation ethic. In S. Kellert \& E. Wilson (Eds.), The biophilia hypothesis. Washington DC: Island Press.

32.Wilson, R. (Ed.) (1994). Environmental education at the early childhood level. Washington, DC: North American Association for Environmental Education. 